\title{
Comprehensive Geriatric Assessment in the Emergency Department for Identifying Elderly Individuals at Risk of Hip Fracture
}

Pei-Ying Lin

Taipei Veterans General Hospital

Hsien-Hao Huang

Taipei Veterans General Hospital

David Hung-Tsang Yen ( $\sim$ hjyen@vghtpe.gov.tw )

Taipei Veterans General Hospital

\section{Research Article}

Keywords: Elderly, comprehensive geriatric assessment, hip fracture, emergency department, risk factors

Posted Date: January 27th, 2021

DOl: https://doi.org/10.21203/rs.3.rs-148820/v1

License: (c) (i) This work is licensed under a Creative Commons Attribution 4.0 International License. Read Full License 


\section{Abstract}

\section{Background}

Hip fracture (HF) is a major challenge for healthcare systems in terms of increased costs and lengths of stay, and it has been estimated that by 2050 , half of the projected 6.26 million global HFs will occur in Asia. Owing to the high morbidity and mortality associated with HF in elderly individuals, it is crucial to recognize at-risk elderly patients in the ED so that special precautions and preventive measures can be taken. While comprehensive geriatric assessment (CGA) has been shown to improve outcomes and prevent secondary fractures in elderly individuals with HF in outpatient settings, there is a lack of data to support the use of CGA in the emergency department (ED) to identify elderly Asian patients who are at risk of HF.

\section{Aim}

To identify the characteristics of elderly Asian patients in the ED who have an increased risk of HF via CGA.

\section{Methods}

A case-control study was conducted in the ED at Taipei Veterans General Hospital, a medical center located in Taipei, Taiwan, from October 2018 to December 2019. Patients $\geq 75$ years old with and without HF were compared using data obtained from CGAs conducted by trained nurses.

\section{Results}

A total of $85 \mathrm{HF}$ patients (cases) and 680 non-HF patients were enrolled, among whom 85 non-HF control individuals (controls) were selected by simple random sampling. HF occurred more frequently in women and in patients with depressive symptoms. An association between decreased handgrip strength and HF risk, especially in men, was also identified $(P<0.001)$. The variables independently associated with the presence of $\mathrm{HF}$ in the multivariate analysis were female sex (odds ratio $(\mathrm{OR})=2.937 ; 95 \% \mathrm{Cl}=1.519$ $5.677)$ and decreased handgrip strength $(\mathrm{OR}=3.739 ; 95 \% \mathrm{Cl}=1.641-8.519)$.

\section{Conclusions}

By performing CGAs in the ED, we found that female sex and decreased handgrip strength were associated with HF risk. Therefore, we propose that targeted assessment of handgrip strength in female patients aged $\geq 75$ years in the ED may identify those at greatest risk of HF, resulting in improved emergency care for geriatric patients.

\section{Introduction}

Hip fracture (HF), particularly in elderly individuals ( $>75$ years old), is a public health problem that has significant effects on both the affected patients and the healthcare system. Elderly patients with HF often 
experience chronic pain and disability; diminished quality of life; cardiovascular, pulmonary, thrombotic, infectious, and bleeding complications; and even an increased risk of death ${ }^{1}$. In terms of the impact on the healthcare system, HF increased hospitalized costs and lengths of stay in elderly. Moreover, it has been estimated that by 2050, half of the projected 6.26 million HF cases worldwide will occur in Asia ${ }^{2}$. According to open data from the Taiwan Ministry of Health and Welfare, there were 10,014 incident cases of HF in Taiwan in 2018, accounting for $0.15 \%$ of emergency department (ED) visits and costing approximately $1,108,000$ USD $^{3}$. Therefore, it is important to develop approaches to effectively predict the risk of HF in elderly individuals, especially in Asia and under time-limited ED conditions.

Comprehensive geriatric assessment (CGA) is a multidisciplinary diagnostic process that evaluates frailty, functional impairment, mental health, cognitive impairment, polypharmacy, environmental risks, nutritional status and social situation in elderly patients to establish interventions, improve quality of care and ultimately improve outcomes ${ }^{4}$. Several approaches involving the management of elderly HF patients by both geriatric and orthopedic specialists have been reported recently ${ }^{5}$; these approaches, tailored for use before surgery, after surgery and before patient discharge, have been shown to improve outcomes and enable the secondary prevention of fragility fractures in geriatric HF patients. Additionally, the utility of CGA in predicting HF in community-dwelling elderly people was described in one cross-sectional study, which revealed that characteristics such as low weight, muscle weakness, disability, and malnutrition could help identify elderly people at increased HF risk ${ }^{6}$.

Nevertheless, there is a lack of data on the use of CGAs in geriatric Asian patients in EDs to assess HF risk. Given the limited time and human resources in ED settings, an evaluation of CGA implementation in the ED will help enable ED care providers to identify geriatric patients who have an increased risk of HF and initiate additional prevention, evaluation and management strategies at the primary care level.

Therefore, the aim of this study was to investigate the ability of CGA to identify characteristics associated with an increased risk of $\mathrm{HF}$ in elderly individuals in the ED.

\section{Methods}

\section{Study participants}

This case-control study was conducted in the ED at Taipei Veterans General Hospital, Taipei, Taiwan, a medical center with an ED capacity of approximately 83,000 visits annually.

From October 2018 to December 2019, all patients aged 75 years and older who visited the observation room of the ED for any indication, were in stable clinical condition, were willing to provide written informed consent, and could complete the CGA assessment were included. The following groups of patients were excluded from the study: (1) patients who were unconscious or uncooperative; (2) patients who had been diagnosed with malignant tumors within the past 3 years who were not in a stable disease state, were likely suffering from pathological fracture or needed tumor-related treatment; (3) patients with autoimmune disease who were not in a stable disease state and required immunosuppressive agents to 
reach therapeutic targets; (4) patients who used high-flow oxygen supplementation and were unable to talk normally without oxygen; (5) patients who revisited the ED within 3 days or who had been previously enrolled in this study; (6) patients who were unwilling to participate in the trial or refused to provide written informed consent; or (7) patients who were discharged before the CGA could be completed.

\section{Comprehensive geriatric assessment}

All eligible subjects underwent CGAs conducted by nurses on the research team within the first 24 hours of ED admittance. The research nurses were well trained in the data collection protocol of the study; they collected the following demographic data, which were self-reported by the patients or their caregivers: age, educational level, marital status, living floor, and living arrangement. The nurses also collected the following clinical data: body mass index $\left(\mathrm{kg} / \mathrm{m}^{2}\right)$, weight loss in the past year, calf circumference $(\mathrm{cm})$, Charlson comorbidity index $(\mathrm{CCl})$, polypharmacy (defined as currently using $>4$ drugs for $>2$ weeks), insomnia, incontinence, mobility difficulties, falls in the past year, cognitive impairment (defined as a score $<24$ on the Chinese version of the Mini-Mental State Examination [MMSE]), depressive symptoms (defined by a score $>5$ on the 15-item Chinese Geriatric Depression Scale [GDS]), malnutrition status (defined by a score < 12 on the Mini Nutritional Assessment-Short Form [MNA-SF]), the baseline activities of daily living ( $A D L$ ) score (assessed by the Barthel Index), and the instrumental activities of daily living (IADL) score (assessed by the Lawton-Brody IADL scale). These parameters were collected from the medical record or measured directly by the research nurses. A validated standardized scoring system ${ }^{7}$ was used to characterize frailty based on age-associated declines in 5 domains: shrinking (body weight loss), weakness (grip strength measured by a TTM Digital Hand Grip Dynamometer; decreased grip strength defined as $<26 \mathrm{~kg}$ for males, and $<18 \mathrm{~kg}$ for females according to the Asian Working Group for Sarcopenia (AWGS) definition ${ }^{8}$ ), exhaustion (effort and motivation), low physical activity (defined as burning $<383 \mathrm{kcal} /$ week for males and $<270 \mathrm{kcal} /$ week for females during leisure time activities), and

slow walking speed (inability to walk, or and up and go test time $\geq 30$ seconds) ${ }^{7}$. Frailty was defined as a score $\geq 3$. Associations of HF risk with both frailty and its component domains were assessed.

\section{HF diagnosis and control selection}

After the CGA was performed in the ED, the diagnosis of HF was determined by emergency specialists and orthopedists, who were blinded to the CGA results, evaluated a cross-table lateral view of the hip and an anteroposterior view of the pelvis, as appropriate. Patients diagnosed with HF were assigned to the HF group (cases), and patients without HF were assigned to the non-HF group. Simple random sampling was performed to select patients in the non-HF group to achieve a 1:1 ratio of cases and controls. The distributions of all variables collected as part of the CGA were compared between the case and control groups.

\section{Statistical analysis}


All continuous variables are presented as the means \pm standard deviations, and categorical data are presented as numbers (percentages). Student's t-test was used to compare continuous variables between the case and control groups, and the chi-square test or Fisher's exact test was used to compare categorical variables between the cases and controls, as appropriate. Variables with statistical significance $(p<0.05)$ were selected for inclusion in the multivariate analysis; logistic regression with forward and backward elimination was performed to identify the factors independently associated with increased HF risk. All statistical analyses were performed using the International Business Machines Corporation Statistical Package for the Social Sciences (IBM SPSS) Statistics for Windows, version 21.0 (IBM Corp., Armonk, NY).

\section{Results}

A total of 6452 elderly patients aged $\geq 75$ years were screened in the observation room of the ED from October 2018 to December 2019 (Fig. 1). A total of 3640 (56.4\%) ineligible patients were excluded. Additionally, 1795 (27.8\%) patients refused to provide informed consent, and 234 (3.6\%) patients were discharged before the researchers could conduct the CGA and evaluate HF. Finally, 783 (12.1\%) elderly patients were enrolled and received a CGA. The CGAs took approximately 30 mins in the observation room; they were performed within 12-24 hours after ED arrival, during office hours (8:00 a.m. to 5:30 p.m., Monday through Friday; 8:00 a.m. to 12:00 p.m., Saturday). Among the 783 patients who received CGAs, 85 (10.9\%) were diagnosed with HF, while 608 (89.1\%) had no evidence of HF. Of the 608 patients without HF, 85 were selected as controls by simple random sampling and included in the subsequent analyses.

The average age of the 170 elderly patients included in the study was $84.2 \pm 7.3$ years; 96 (56.5\%) were male, and 74 (43.5\%) were female. Most of the patients were married (95\%). Approximately $40 \%$ lived on the second floor or above with no access to an elevator, and the majority lived with others (i.e., caregivers or unrelated nursing workers) (Table 1).

Compared with the control group, the cases had higher proportions of women ( $57.6 \%$ vs. $42.4 \%, p<$ $0.001)$, individuals with depressive symptoms (GDS- $5 \geq 2)(36.4 \%$ vs. $20.3 \%, p=0.034)$ and individuals with decreased handgrip strength ( $88.1 \%$ vs. $65.1 \%, p<0.001)$, especially in men ( $17.2 \pm 6.1$ vs. $22.4 \pm 7.6$ $\mathrm{kg}, \mathrm{p}=0.001$ for men; $11.8 \pm 5.1$ vs. $13.5 \pm 5.3 \mathrm{~kg}, \mathrm{p}=0.186$ for women). There were no significant differences in sex, $\mathrm{CCl}$ score, height, weight, BMI, calf circumference, Barthel index, IADL score, MMSE score, nutritional status, frailty, polypharmacy, insomnia, incontinence, mobility difficulties, falls in the past year, weight loss $\geq 5 \mathrm{~kg}$ in the past year, and physical activity between the cases and controls (Table 2).

We entered the variables with significant differences between the case and control groups (sex, GDS score, and decreased handgrip strength) into the multiple logistic regression model with a backward stepwise approach. The independent predictors of HF in elderly patients in the ED were female sex (odds 
ratio [OR], 2.937; 95\% confidence interval [Cl], 1.519-5.677; $p=0.001)$ and decreased handgrip strength (OR, 3.739; 95\% Cl, 1.641-8.519; $\mathrm{p}=0.002$ ) (Table 3).

\section{Table 1}

Demographic characteristics of geriatric patients in the ED included in the analysis. 


\begin{tabular}{|c|c|}
\hline & $\begin{array}{l}\text { Total } \\
(n=170)\end{array}$ \\
\hline Age (y) & $84.2 \pm 7.3$ \\
\hline \multicolumn{2}{|l|}{ Sex } \\
\hline Male & $96(56.5)$ \\
\hline Female & $74(43.5)$ \\
\hline \multicolumn{2}{|l|}{ Education level } \\
\hline No formal education & $25(14.8)$ \\
\hline Self-taught & $8(4.7)$ \\
\hline Elementary school & $53(31.4)$ \\
\hline Junior high school & $35(20.7)$ \\
\hline Senior high school & $21(12.4)$ \\
\hline University or above & $27(16)$ \\
\hline \multicolumn{2}{|l|}{ Marital status } \\
\hline Single & $15(8.8)$ \\
\hline Married & $95(55.9)$ \\
\hline Widowed/divorced & $60(35.3)$ \\
\hline \multicolumn{2}{|l|}{ Living floor } \\
\hline First floor & $42(24.7)$ \\
\hline Apartment with an elevator & $61(35.9)$ \\
\hline Second floor or above without an elevator & $67(39.4)$ \\
\hline \multicolumn{2}{|l|}{ Living arrangement } \\
\hline Alone & $15(8.8)$ \\
\hline With family & $12(7.1)$ \\
\hline A home for veterans & $4(2.4)$ \\
\hline A nursing home & $5(2.9)$ \\
\hline With others & $134(78.8)$ \\
\hline
\end{tabular}


Table 2

Comparison of demographic and clinical data between the cases (with hip fracture) and controls (without hip fracture).

\begin{tabular}{|c|c|c|c|c|}
\hline & $\begin{array}{l}\text { All } \\
(n=170)\end{array}$ & $\begin{array}{l}\text { Patients } \\
\text { without } \\
\text { HF (controls) } \\
(n=85)\end{array}$ & $\begin{array}{l}\text { Patients with HF } \\
\text { (cases) } \\
(n=85)\end{array}$ & P-value \\
\hline Age $($ mean \pm SD $)$ & $84.2 \pm 7.3$ & $84.9 \pm 6.2$ & $83.6 \pm 8.3$ & 0.259 \\
\hline Sex & & & & $\hat{0}_{0.001 *}$ \\
\hline Male & $96(56.5)$ & $60(70.6)$ & $36(42.4)$ & \\
\hline Female & $74(43.5)$ & $25(29.4)$ & $49(57.6)$ & \\
\hline $\mathrm{CCl}($ mean $\pm \mathrm{SD})$ & $1.5 \pm 1.4$ & $1.4 \pm 1.2$ & $1.6 \pm 1.5$ & 0.499 \\
\hline Height (cm) & $\begin{array}{l}159.3 \pm \\
9.0\end{array}$ & $160.5 \pm 9.4$ & $158.2 \pm 8.5$ & 0.110 \\
\hline Weight (kg) & $\begin{array}{l}59.5 \pm \\
12.3\end{array}$ & $61.2 \pm 11.7$ & $58.1 \pm 12.6$ & 0.131 \\
\hline BMI & $23.3 \pm 3.9$ & $23.7 \pm 3.7$ & $22.9 \pm 4.1$ & 0.260 \\
\hline Calf circumference (cm) & $29.8 \pm 3.4$ & $30.1 \pm 3.6$ & $29.5 \pm 3.3$ & 0.392 \\
\hline Barthel index (mean \pm SD) & $\begin{array}{l}86.4 \pm \\
19.3\end{array}$ & $87.0 \pm 20.9$ & $85.8 \pm 17.7$ & 0.687 \\
\hline IADL score $($ mean \pm SD $)$ & $4.5 \pm 2.5$ & $4.6 \pm 2.5$ & $4.4 \pm 2.6$ & 0.662 \\
\hline MMSE score (mean \pm SD) & $19 \pm 6.3$ & $19.4 \pm 6.4$ & $18.5 \pm 6.2$ & 0.366 \\
\hline GDS-5 score $\geq 2$ & $39(27.9)$ & $15(20.3)$ & $24(36.4)$ & $0.034^{*}$ \\
\hline MNA-SF result & & & & 0.638 \\
\hline Normal nutrition & $52(31.9)$ & $29(34.5)$ & $23(29.1)$ & \\
\hline At risk of malnutrition & $82(50.3)$ & $42(50)$ & $40(50.6)$ & \\
\hline Malnutrition & $29(17.8)$ & $13(15.5)$ & $16(20.3)$ & \\
\hline
\end{tabular}

Data are presented as numbers (\%) unless otherwise indicated.

* indicates statistical significance $(P<0.05)$.

$\mathrm{HF}$, hip fracture; $\mathrm{CCl}$, Charlson comorbidity index; IADL, Lawton-Brody instrumental activities of daily living; MMSE, Mini-Mental State Examination; GDS-5, 5-item Geriatric Depression Scale (a score $\geq 2$ indicates depressive symptoms); MNA-SF, Mini Nutritional Assessment-Short Form; decreased handgrip strength, male $<26 \mathrm{~kg}$, female $<18 \mathrm{~kg}$; polypharmacy, score $\geq 5$. 


\begin{tabular}{|c|c|c|c|c|}
\hline & $\begin{array}{l}\text { All } \\
(n=170)\end{array}$ & $\begin{array}{l}\text { Patients } \\
\text { without } \\
\text { HF (controls) } \\
(n=85)\end{array}$ & $\begin{array}{l}\text { Patients with HF } \\
\text { (cases) } \\
(n=85)\end{array}$ & P-value \\
\hline Frailty & $90(55.6)$ & $40(48.2)$ & $50(63.3)$ & 0.053 \\
\hline Decreased handgrip strength & $\begin{array}{l}128 \\
(76.6)\end{array}$ & $54(65.1)$ & $74(88.1)$ & $\begin{array}{l}< \\
0.001 *\end{array}$ \\
\hline Men $(\mathrm{kg})($ mean $\pm S D)$ & $20.4 \pm 7.5$ & $22.4 \pm 7.6$ & $17.2 \pm 6.1$ & $0.001 *$ \\
\hline Women $(\mathrm{kg})($ mean \pm SD) & $13.4 \pm 5.2$ & $13.5 \pm 5.3$ & $11.8 \pm 5.1$ & 0.186 \\
\hline Polypharmacy & 78 (49.4) & $37(49.3)$ & $41(49.4)$ & 0.633 \\
\hline Insomnia & $60(35.5)$ & $26(31)$ & $34(40)$ & 0.219 \\
\hline Incontinence & $34(20)$ & $15(17.6)$ & $19(22.4)$ & 0.443 \\
\hline Mobility difficulties & $93(55)$ & $41(48.8)$ & $52(61.2)$ & 0.106 \\
\hline Fall in the past year & $54(32.1)$ & $25(29.4)$ & $29(34.9)$ & 0.443 \\
\hline $\begin{array}{l}\text { Weight loss } \geq 5 \mathrm{~kg} \text { in the past } \\
\text { year }\end{array}$ & $13(8.7)$ & $8(10.4)$ & $5(6.9)$ & 0.456 \\
\hline Low physical activity & $84(51.9)$ & $41(49.4)$ & $43(54.4)$ & 0.522 \\
\hline \multicolumn{5}{|c|}{ Data are presented as numbers (\%) unless otherwise indicated. } \\
\hline \multicolumn{5}{|c|}{ * indicates statistical significance $(P<0.05)$} \\
\hline \multicolumn{5}{|c|}{$\begin{array}{l}\mathrm{HF} \text {, hip fracture; } \mathrm{CCl} \text {, Charlson comorbidity index; IADL, Lawton-Brody instrumental activities of daily } \\
\text { living; MMSE, Mini-Mental State Examination; GDS-5, 5-item Geriatric Depression Scale (a score } \geq 2 \\
\text { indicates depressive symptoms); MNA-SF, Mini Nutritional Assessment-Short Form; decreased } \\
\text { handgrip strength, male }<26 \mathrm{~kg} \text {, female }<18 \mathrm{~kg} \text {; polypharmacy, score } \geq 5 \text {. }\end{array}$} \\
\hline
\end{tabular}

Table 3

Regression analysis results.

\section{Chi-square test}

\section{Variable}

Women (relative to men)

Decreased handgrip strength
Multivariate logistic regression

OR $\quad 95 \% \mathrm{Cl}$ of OR $\quad \mathrm{p}$-value

2.937

[1.519-5.677]

0.001

3.739

[1.641-8.519]

0.002

Backward and forward elimination (conditional on $p<0.05$ ): sex, GDS score, and decreased handgrip strength were entered; sex and decreased hand grip strength remained in the model. 


\section{Discussion}

While the use of CGA in the ED has previously been proposed ${ }^{4}$ based on the demonstrated feasibility and effectiveness of CGA in outpatient orthogeriatric units ${ }^{6}$, evidence to support its use in the ED, particularly in relation to identifying patients at risk of HF, is lacking. As such, this study conducted CGAs in patients $\geq 75$ years old in the ED. Consistent with the results of recent observational studies, we found that the incidence of HF was higher in women than in men ${ }^{6,10-12}$ and in elderly individuals with decreased handgrip strength than in those with normal handgrip strength $6,11,13$.

In our study, female sex was an independent risk factor for HF, with an OR of 2.937 according to the multivariate logistic regression model; this result was consistent with that of one systematic review that reported that the incidence of HF was twice as high in women than in men worldwide ${ }^{13}$. Moreover, among East Asian populations, females have a higher incidence of HF in China ${ }^{14}, \mathrm{Japan}^{15}{ }^{15} \mathrm{Korea}^{16}$, and Taiwan $^{17}$. It is well known that females have a higher risk of osteoporosis than males ${ }^{18}$, and osteoporosis leads to a subsequent elevated risk of HF in females ${ }^{19}$.

Grip strength has been proposed as an indicator of overall muscle strength and general health in elderly individuals ${ }^{20}$, moreover, an association between decreased handgrip strength and $\mathrm{HF}$ has been reported ${ }^{21}$. One systematic review including 11 studies showed that decreased handgrip strength was related to a 0.7 -fold to 49.5-fold increase in HF according to different cutoff values and in different populations ${ }^{21}$. Consistent with these results, our study found that decreased grip strength (with a cutoff value of $26 \mathrm{~kg}$ for men and $18 \mathrm{~kg}$ for women, as recommended by the AWGS 2014 guidelines $^{8}$ ) in elderly individuals was associated with a nearly 4 -fold increased probability of $\mathrm{HF}(\mathrm{OR}=3.739,95 \% \mathrm{Cl}=1.641$, 8.519), in the multiple logistic regression analysis of our patient population.

Additionally, decreased handgrip strength was associated with reduced mobility, osteoporosis, and increased falls in a recent review article ${ }^{20}$ and was considered a criterion for diagnosing sarcopenia ${ }^{8}$, which, together with osteoporosis, was associated with an increased HF risk ${ }^{22,23,24}$. One study further demonstrated that a maximum handgrip strength $<20 \mathrm{~kg}$ in 65 -year-old women was a risk factor for HF according to logistic analysis, echoing these previous studies.

In accordance with previously reported results ${ }^{27}$, our study found that symptoms of depression were associated with HF risk in the univariate analysis. However, this variable did not remain significant in the multivariate analysis, probably because of the use of different measurements of depression (International Classification of Disease- 10 codes in the previous study ${ }^{27}$ vs. GDS- 5 criteria in our study) and different populations (nationwide cohort population ${ }^{27}$ vs. an ED population, respectively). Additionally, the previous study was a health insurance database analysis; multiple regression analysis was not performed and, therefore, the study was unable to identify independent factors of HF. Our study demonstrated that depression was not an independent risk factor for HF in the multivariate analysis. 
Moreover, in contrast with the results of multiple studies that reported correlations between frailty and $\mathrm{HF}^{28-30}$, our study results showed no significant difference in frailty between the cases and controls. The only significant frailty domain was weakness (decreased handgrip strength), indicating that handgrip strength itself was a better predictive measure for HF than general frailty in our study population.

One of the primary strengths of this study is that, to our knowledge, this is the first study in Asia to use CGA as a tool to assess elderly patients in the ED to identify patients with a high HF risk. We demonstrated that CGA focusing on handgrip strength assessment in female patients aged $\geq 75$ years is a widely available, effective, low-cost tool that can be performed in a bustling ED; this tool makes good use of limited ED human resources and can easily identify elderly individuals who are at risk of HF. In addition, our patient population was older than those in other recent studies ${ }^{10,11,21,28-30}$ (mean: 84.2 vs. 76.4-82.7 years old, respectively); therefore, our study might serve as a reference for the evaluation of the oldest members of the elderly population. In particular, the CGA components relevant to HF risk in this study are easily measured in the oldest members of the elderly population, including those with a reduced ability to communicate.

Our study has several limitations. First, this study was conducted in a single urban medical center; therefore, the results may not be generalizable to other settings. Second, the rate of unwillingness to participate in the trial (63.8\% in eligible patients) was high, which may have resulted in patient selection bias; the reason for refusal was not recorded consistently. Third, in our study, there were no significant differences in the Barthel index, nutritional status or MMSE score between the patient groups with and without HF, possibly due to extreme old age and cognitive impairment-related reporting bias (the mean MMSE was < 24 in both groups) in our patient population. Optimized scales and data sources, such as medical records, home care diaries, and scales observed by caregivers, might be needed for more objective assessments in the future.

\section{Conclusion}

By performing CGAs in the ED, we were able to identify patients with an increased risk of HF with two easily assessed factors: female sex and decreased handgrip strength. Therefore, we propose that a targeted assessment of handgrip strength in female patients aged $\geq 75$ years may identify patients at greatest risk of HF in the ED. Once these patients are identified, early geriatric and orthopedic specialists involvement, preventive measures such as such as providing instructions including home safety improvements, proper exercise to maintain muscle strength, and medicine precautions with side effect of unsteadiness, would potentially change the course of care in the ED and enable improved emergency care.

\section{Declarations}

\section{Ethics approval and consent to participate}


The study protocol was reviewed and approved by the Ethics Committee of Taipei Veterans General Hospital (approval number: 2018-03-011CC) and all procedures performed in studies involving human participants were in accordance with the ethical standards of the institutional research committee and with the 1964 Helsinki declaration and its later amendments. Informed consent was obtained from all individual participants included in the study.

\section{Consent for publication}

All authors consent to the publication of the manuscript in BMC Geriatrics. The article has not been previously published elsewhere, and the manuscript is not under consideration for publication in another journal, and will not be submitted elsewhere until the BMC Geriatrics editorial process is completed.

\section{Availability of data and materials}

The datasets generated and analyzed during the current study are available from the corresponding author, David Hung-Tsang Yen, upon reasonable request.

\section{Competing interests}

This work was not supported by any company. We declare that all authors consent to the submission of this manuscript, and no author has a personal conflict of interest at the time of publication of the material.

\section{Funding}

This research received no funding form the commercial, public, or not-for-profit sectors.

\section{Authors' contributions}

Lin Pei-Ying wrote the main manuscript text, and both Hsien-Hao Huang, David Hung-Tsang Yen conceived and designed the analysis, and prepared table 1 and figures 1-3. All authors reviewed the manuscript.

\section{Acknowledgements}

We would like to thank the following people for their assistance with the collection of our data: Zhi-Yu Yang, Yu-Jie Yang, and Hui-Jia Liu. We also like to express our great appreciation to Department of 
Emergency Medicine, Taipei Veterans General Hospital, Taiwan, for support and allowing us to conduct this study.

\section{References}

1. Carpintero P, Caeiro JR, Carpintero R, Morales A, Silva S, Mesa M. Complications of hip fractures: A review. World J Orthop. 2014 Sep 18;5(4):402-11.

2. Dhanwal DK, Dennison EM, Harvey NC, Cooper C. Epidemiology of hip fracture: Worldwide geographic variation. Indian J Orthop. 2011 Jan;45(1):15-22.

3. Taiwan ministry of health and welfare. https://dep.mohw.gov.tw/DOS/cp-4648-50670-113.html

4. Ellis $\mathrm{G}$, Marshall T. Comprehensive geriatric assessment in the emergency department. Clin Interv Aging. 2014 Nov 24;9:2033-43.

5. De Rui M, Veronese N, Ritchie C. Role of comprehensive geriatric assessment in the management of osteoporotic hip fracture in the elderly: an overview. Disabil Rehabil. 2013 May;35(9):758-65.

6. Ramírez-Martín R, Castell Alcalá MV, Alarcón T, et al. Comprehensive geriatric assessment for identifying older people at risk of hip fracture: cross-sectional study with comparative group. Fam Pract. 2017;34(6):679-684.

7. Fried LP, Tangen CM, Walston J, Newman AB, Hirsch C, Gottdiener $\mathrm{J}$ et al. Frailty in older adults: evidence for a phenotype. J Gerontol A Biol Sci Med Sci 2001;56(3):M146-57.

8. Chen LK, Liu LK, Woo J, et al. Sarcopenia in Asia: consensus report of the Asian Working Group for Sarcopenia. J Am Med Dir Assoc. 2014;15(2):95-101.

9. Rubenstein LZ, Josephson KR, Wieland GD, English PA, Sayre JA, Kane RL. Effectiveness of a geriatric evaluation unit. A randomized clinical trial. N Engl J Med 1984;311:1664-1670.

10. Lan TY, Hou SM, Chen CY, et al. Risk factors for hip fracture in older adults: a case-control study in Taiwan. Osteoporos Int. 2010;21(5):773-784.

11. Abey-Nesbit R, Schluter PJ, Wilkinson T, Thwaites JH, Berry SD, Jamieson HA. Risk factors for hip fracture in New Zealand older adults seeking home care services: a national population crosssectional study. BMC Geriatr. 2019;19(1):93.

12. Wiklund R, Toots A, Conradsson M, et al. Risk factors for hip fracture in very old people: a populationbased study. Osteoporos Int. 2016;27(3):923-931.

13. Kanis JA, Odén A, McCloskey EV, Johansson H, Wahl DA, Cooper C; IOF Working Group on Epidemiology and Quality of Life. A systematic review of hip fracture incidence and probability of fracture worldwide. Osteoporos Int. 2012 Sep;23(9):2239-56.

14. Xia WB, He SL, Xu L, Liu AM, Jiang Y, Li M, Wang O, Xing XP, Sun Y, Cummings SR. Rapidly increasing rates of hip fracture in Beijing, China. J Bone Miner Res. 2012 Jan;27(1):125-9.

15. Orimo H, Yaegashi Y, Hosoi T, Fukushima Y, Onoda T, Hashimoto T, Sakata K. Hip fracture incidence in Japan: Estimates of new patients in 2012 and 25-year trends. Osteoporos Int. 2016 May;27(5):1777-84. 
16. Ha YC, Park YG, Nam KW, Kim SR. Trend in hip fracture incidence and mortality in Korea: a prospective cohort study from 2002 to 2011. J Korean Med Sci. 2015 Apr;30(4):483-8.

17. Chen FP, Shyu YC, Fu TS, Sun CC, Chao AS, Tsai TL, Huang TS. Secular trends in incidence and recurrence rates of hip fracture: a nationwide population-based study. Osteoporos Int. 2017 Mar;28(3):811-818.

18. Li L, Wang Z. Ovarian Aging and Osteoporosis. Adv Exp Med Biol. 2018;1086:199-215. doi: 10.1007/978-981-13-1117-8_13. PMID: 30232761

19. Orwig DL, Chan J, Magaziner J. Hip fracture and its consequences: differences between men and women. Orthop Clin North Am. 2006 Oct;37(4):611-22.

20. Bohannon RW. Grip Strength: An Indispensable Biomarker For Older Adults. Clin Interv Aging. 2019 Oct 1;14:1681-1691.

21. Denk K, Lennon S, Gordon S, Jaarsma RL. The association between decreased hand grip strength and hip fracture in older people: A systematic review. Exp Gerontol. 2018;111:1-9.

22. A. Oliveira, C. Vaz The role of sarcopenia in the risk of osteoporotic hip fracture. Clin. Rheumatol., 34 (2015), pp. 1673-1680

23. Li YZ, Zhuang HF, Cai SQ, Lin CK, Wang PW, Yan LS, Lin JK, Yu HM. Low grip strength is a strong risk factor of osteoporosis in postmenopausal women. Orthop Surg. 2018 Feb;10(1):17-22.

24. L. Joseph Melton, lii, Heinz W. Wahner, Linda S. Richelson, W. Michael O'fallon, B. Lawrence Riggs, osteoporosis and the risk of hip fracture, American Journal of Epidemiology, Volume 124, Issue 2, August 1986, Pages 254-261

25. Finsterwald M, Sidelnikov E, Orav EJ, et al. Gender-specific hip fracture risk in community-dwelling and institutionalized seniors age 65 years and older. Osteoporos Int. 2014;25(1):167-176.

26. Elliot JR, Hanger HC, Gilchrist NL, et al. A comparison of elderly patients with proximal femoral fractures and a normal elderly population: a case control study. N Z Med J. 1992;105(944):420-422.

27. Kim SY, Lee JK, Oh DJ, Kong IG, Choi HG. Depression and incident hip fracture: A longitudinal followup study using a national sample cohort. Medicine (Baltimore). 2019;98(26):e16268.

28. Ensrud KE, Ewing SK, Cawthon PM, Fink HA, Taylor BC, Cauley JA, Dam TT, Marshall LM, Orwoll ES, Cummings SR; Osteoporotic Fractures in Men Research Group. A comparison of frailty indexes for the prediction of falls, disability, fractures, and mortality in older men. J Am Geriatr Soc. 2009 Mar;57(3):492-8.

29. Ensrud KE, Ewing SK, Taylor BC, et al. Comparison of 2 frailty indexes for prediction of falls, disability, fractures, and death in older women. Arch Intern Med. 2008;168(4):382-389.

30. Correa-de-Araujo R. An operational definition of frailty predicted death, hip fracture, and hospitalization in older women. ACP J Club. 2006;144(1):23.

\section{Figures}




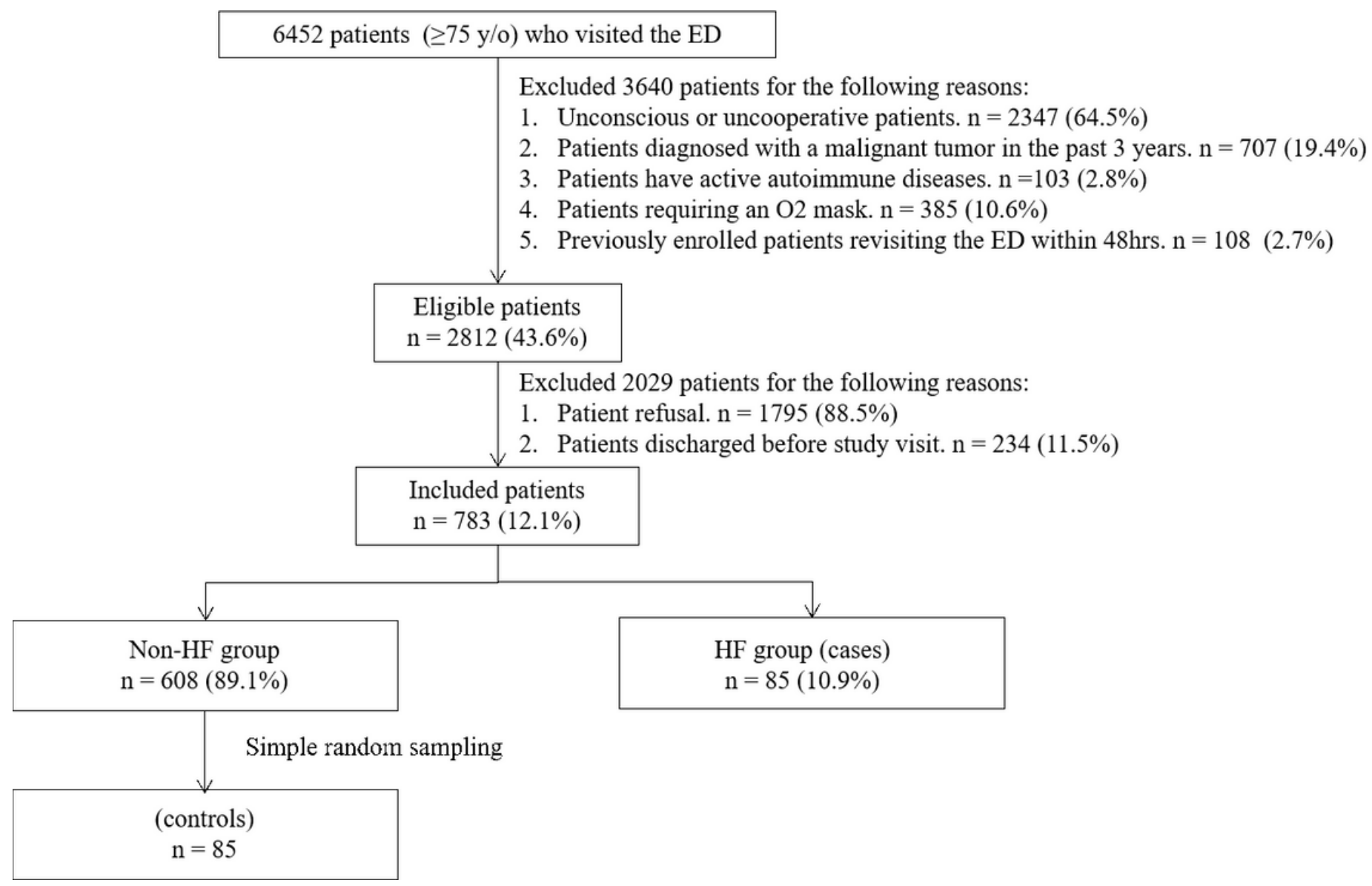

Figure 1

Study flow diagram. ED, emergency department; HF, hip fracture; CGA, comprehensive geriatric assessment 